\title{
The span of the effective stimulus during a fixation in reading
}

\author{
GEORGE W. McCONKIE \\ Cornell University, Ithaca, New York 14850 \\ and \\ KEITH RAYNER \\ University of Rochester, Rochester, New York 14627
}

\begin{abstract}
A computer-based eye-movement controlled display system was developed for the study of perceptual processes in reading. A study was conducted to identify the region from which skilled readers pick up various types of visual information during a fixation while reading. This study involved making display changes, based on eye position, in the text pattern as the subject was in the act of reading from it, and then examining the effects these changes produced on eye behavior. The results indicated that the subjects acquired word-length pattern information at least 12 to 15 character positions to the right of the fixation point, and that this information primarily influenced saccade lengths. Specific letter- and word-shape information were acquired no further than 10 character positions to the right of the fixation point.
\end{abstract}

Psychologists have long been interested in the question posed by Woodworth (1938) in his review of research on reading: "How much can be read in a single fixation?" The investigation of this question has a long history, dating back to some of the earliest research on reading. Cattell, in 1885 (summarized by Huey, 1908), provided data on the number of letters that could be reported following a tachistoscopic presentation of letter strings of different types. Since then, a number of studies have been conducted to investigate this question. If a person fixates a letter on a page of text, he often finds that he can recognize words two or even three lines above and below the one being fixated, as well as words some distance to the left and right. Beyond that, punctuation marks, capital letters, and the beginnings and ends of paragraphs are visible. On the other hand, if a string of random letters is presented visually by means of a tachistoscope, a person is likely to be able to identify

The research described in this report was carried out at the Artificial Intelligence Laboratory at the Massachusetts Institute of Technology. The authors wish to express their gratitude to Dr. Marvin Minsky and Mr. Russell Noftsker for the use of the extensive computer facilities at the Al Lab. David Silver, a staff programmer there, did much of the programming involved. and his assistance is greatly appreciated. Gary Wolverton, a graduate student at Cornell University, provided assistance with much of the data analysis. The research was made possible by a Special Fellowship from the National Institute of Mental Health to the senior author and by Grant OEG-2-71-0531 from the Office of Education. Portions of these data were reported at the 1973 meetings of the Eastern Psychological Association and the American Educational Research Association. Reprints may be obtained by writing to George W. McConkie, 214 Stone Hall, Cornell University, Ithaca, New York 14850. only four to six letters. The answer to the question, then depends on the type of materials used and the presentation and task conditions.

While the studies that have been conducted on this question have yielded information about how much it is possible to see and to report from a single fixation, and how far into the periphery of the retina visual information can be identified, they fail to resolve the original concern about reading. A better statement of the original question, as it relates to reading, would probably be, "How far into the periphery are specific aspects of the visual stimulus typically acquired and used during fixations in reading?" This restatement differs from the original question in several respects. First, it recognizes that different types of visual information might be available and used by the reader in different retinal areas. Thus, there probably is not a single perceptual span, but a family of spans depending on the aspects of the visual stimulus that are being studied. Second, it notes that there may be a difference between what information is available to the subject during a particular fixation and what he actually acquires and uses for a particular task. Thus, the perceptual span estimates that one obtains from subjects involved in different tasks are likely to differ. This leads to the third point, that in order to answer the perceptual span question about reading, it is necessary to study subjects who are engaged in the act of reading. The major concern for a theory of reading is not what people are capable of seeing during a fixation, but what information they typically acquire and use as they read.

Previous studies of the perceptual span cannot be 
taken as providing a definite answer to our restated question for either of two reasons. Most of these studies have involved subjects in a task quite different from normal reading. typically using single tachistoscopic presentations from which the subject is asked to identify the letters, numbers, or words presented (Bouma, 1973: Mackworth, 1965). Those studies that have involved the reading of passages, on the other hand, have still used tasks which interfere greatly with normal reading behavior (Bouma \& de Voogd. 1974: New man. 1966; Poulton, 1962).

The research to be reported here was an attempt to develop a method for obtaining information about the size of the region from which specitic types of visual information are obtained during fixations while the subjects are involved in reading a passage, with as few constraints on their reading behavior as possible. An eve-movement controlled display system was developed which permitted a computer to frequently sample the reader's eye position as he read from a computer-generated text display on a cathode-ray tube (CRT). With this system, it was possible to modify the text display on the basis of the reader's eye position. The research involved displaying an unreadable pattern on the CRT, with every letter of the original text replaced by another letter. Then, when the subject fixated the first line of text, the display was moditied by replacing letters within a certain region to the left and right of the fixation point on that line with the corresponding letters from the original text. This created a "window" of normal text for the reader on that fixation. When the reader made a saccade, the text in the window returned to its modified form, and a window of normal text was created at the next fixation location. Thus, wherever the reader looked, there was normal text for him to see, allowing him to read quite normally. However, the experimenter could determine the size of the region of normal text, as well as the nature of the pattern beyond this window region.

The experiment involved having subjects read with different-size windows and different peripheral text patterns. The text patterns appearing in peripheral vision (outside the window) maintained or destroyed certain visual characteristics of the original text. It was assumed that if the window were large enough for the reader to obtain all useful visual information within that region, the presence or absence of certain visual characteristics in the region beyond the window would make no difference; that is, data on eye movements and test performance would not be affected. However, if the window were made smaller, a point would be reached where the deletion of those visual characteristics outside the window would interlere with reading; that is, visual information normally obtained and used in reading had been destroyed. Thus, the research strategy was to maintain or destroy certain visual characteristics of the original text in the peripheral text pattern, and then to determine how small the window must be made before a difference in reading was produced by the nature of the peripheral text pattern used. This would indicate how far into the periphery that visual aspect of the text was obtained and used in reading.

\section{METHOD}

\section{Subjects}

Six high school students participated as subjects in the study. All were seniors or juniors and were identitied as being among the best readers in their school. They were paid for participation. receiving a base rate plus a bonus based on their pertormance on test questions. All had participated in an earlier study and were familiar with the equipment and procedures used.

\section{Materials}

Sixteen $\bar{\delta}(0)$-word passages were selected from a high school psychology text. None of the subjects had taken a course in psychology. Each passage was divided into six approximately equal-size pages, which were displayed one at a time. double-spaced, during the experiment.

Six algorithms were used to substitute letters for characters in the original text to produce modified versions of the text. called peripheral text patterns. Six peripheral text patterns were prepared for each passage, conforming to a 2 by 3 design: XS, XF, CS, CF. NCS, and NCF. In the $X$ versions, each letter in the original text was repliced by an $X$. In the $C$ versions. each letter was replaced by a letter visually similar (confusable) with it. The substitutions were taken from confusability matrices developed by Bouma (1971) and Hodge (1962). In the NC versions, each letter was replaced by a letter visually different (nonconfusable) from it. with ascending letters replacied by letters that did not extend above or below the line or by descenders. and with descenders replaced by ascenders or letters that did not extend beyond the line of print. In addition, the $S$ (spaces) form of each of these maintained spaces and punctuation, whereas in the $F$ (filled) form each space and punctuation mark was replaced by an appropriate letter, an $\mathrm{x}$ in the $X F$ version and other letters in the $C F$ and NCF versions. In addition, in the XF version all replacement was done using capital $X s$. thus eliminating capitalivation characteristics. Figure 1 shows a line of normal text and the corresponding line after having letters substituted to produce each of the peripheral text versions.

Two multiple-choice test yilestions were prepared for each page of text, thus yielding 12 questions for each passage. These questions tested retention of information clearly stated in individual sentences in the passage. Each question had four alternatives from which the subject was to choose.

\section{Design}

Forty-cight display conditions were used in this study, produced by factorially combining eight window sizes with six peripheral text patterns. The six peripheral text patterns have already been described: window sizes used were: $13,17,21,25,31,37,45$, and 100 character positions. Thas, for the smalter windows. each successively larger window size extended the window by two character positions at each end. As can be seen in Figure 1, with a windom size of 17 . the character being fixated and eight character positions to the left and right of the fixated character comprise the window.

Facl subject read all 10 passages ( 9 pages). with two of the passages being read under each of the 48 presentation conditions. Ali subjects read the passinges in the same order, but the condition order was unicue for each subject. An attempt was made to balance prescntation conditions over passage and page sequence order as fat as possible. Each presentation condition occurred once in the tirst cight passages, and again in the last eight, for each subject. 


\author{
Graphology means personality diagnosis from hand wrizing. This is a

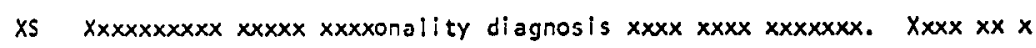

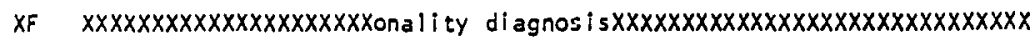 \\ is Cnojkaiazp wsore jsnconality diagnosis tnaw kori miflrz. Ykle le o \\ Cf Crojkaiaqpewsorcejsnconality diagnosisetnawekoriemn ffl rqeecyklee leco \\ NCS HEfxwysyvo tifdl xiblonality diagnosis abyt wfon hbemedv. Awel el $f$ \\ NCF Hbfxwsyvoctifdicxiblonality diagnosiscabytewfonehbemedveecAwcleclof
}

Figure 1. An example of a line of text and the various peripheral text patterns derived from it.

Note. - On each line a window of size 17 is shown, assuming the reader is fixating the letter $d$ in diagnosis.

\section{Procedure}

When a subject arrived for the experiment, a bite bar was prepared for him which served to reduce head movement during the experiment. Then the eve-tracking sensors. mounted on glasses trames and held more securely with a headband, were placed on him and adjusted. He then had the opportunity to warm up by reading two or three passages under cond itions of various window sizes and peripheral text patterns.

Prior to reading each passage, the subject was engaged in 'a calibration task. A target spot appeared on the display, and the subject was instructed to look directly at it and press a lever located next to his right hand. When the lever was pressed. the computer stored the signals being received from the eve-tracking equipment. and mored the target to a new location. This sequence occurred 25 times. giving the computer the values needed for identifying from the eve-position signal where the subject's gaze was directed. An additional push of the lever brought the first page of text on to the CRT. and later pages of a passage were also called by depressing the lever. As the subject read each page. the computer kepr a complete record of the position and duration of each fixation and of the time required tor each saccade. All times were recorded in 60 ths of a second. and later converted to milliseconds. After reading all six pages of a passage. the subject came off the equipment and took a test for that passage. Prior to reading the next passage. the test was scored and he was informed of his score. In order to encourage subjects to put their emphasis on understanding and remembering the content of the passages. they were given 1 cent for each correct answer on the test.

Each subject participated in the study for two 2-h sessions. reading the first eight passages during the first session and the last eight during the second session.

\section{Apparatus}

The equipment used for this research has been described in detail elsewhere (McConkie \& Rayner. Note 1). and is similar to a system described by Reder (19-3). It consisted of a Biometrics Model SG eve-movement monitor interfaced with a Digital Equipment Corporation (DEC) PDP-6 computer. permitting on-line recording of eve movements. The computer also controlled a DEC Model 340 display, which had a character generator for upper-and lowercase letters. The PDP-6 was also interfaced to a PDP-10 time-sharing system. The experiment was conducted using the PDP-6. while the PDP-10 did all tile handling.

The CRT had a displayable area of $20.96 \times 18.42 \mathrm{~cm}$. capable of displaring 40 lines of 80 characters each. Only 8 to 10 lines of text were displayed at once. double spaced. The subject was $53.34 \mathrm{~cm}$ from the CRT. so a full line of text 172 characters) occupied about $18 \mathrm{deg}$ of visual angle. or about four letters per degree. The CRT had a $\mathrm{P}^{-}$phosphor. which is actually composed of two phosphors. one blue-white and of short persistence. the other yellow and of long persistence. A dark blue theater gel was used to filter out the yellow. image. leaving a rapid-decaying image having characteristics similar to those of a P-11 phosphor. There was no noticeable tlicker
The Biometrics ere-movement monitor uses a corneal reflection method of monitoring eye position. There were two problems with its use. First. although it is relatively accurate in identifying eve position on the horizontal dimension. it is quite inaccurate on the vertical dinension. where it monitors position of the eyelid rather than of the eve itselt. When a subject is asked to fixate a target, the computer indicates the eve as being directed to a letter no more than three characters from the target. and almost always within two charater positions $1 "$ deg of visual angle). on the horizontal dimension. The vertical signal was so inaccurate that it was decided to ignore it and to use a heuristic to identify the line being read. It "as assumed that the reader began on the top line. and that a long vertical movement. or series of movements, totaling at least 45 character positions. indicated that he was progressing to the next line. The subjects were instructed to read line by line and not to try to return 10 an earlier line. They were given practice with the equipment and encouraged to try violating these requests, to observe the conditions under which the window would not follow their ere positions. They experienced no difticulty on contirming to these requests. though the number of regressions they typically made was likely reduced.

The second problem with the eye-movement monitoring equipment concerned the great amount of noise in the signal. To reduce this. a filter built into the equipment was left engaged and another added. Following the research. it was learned that the first tilter delayed the signal substantially. Presenting one of the photodiodes in the sensors with a fast-rising infrared signal caused the analogue output from the equipment to begin rising almost inmediately, reaching a maximum level in 4 to $5 \mathrm{msec}$. With the tilter engaged. however. although the output signal began rising almost immediately. it reached maximum level only after $25 \mathrm{msec}$ or more. The second filter delaved the signal less than $1 / 2 \mathrm{msec}$.

The computer was programmed to sample the signal from the eve-movement monitor 60 times per second. On each sample. it was determined whether the eye was moving or still. by comparing the change in the signal since the last sample with a threshold value. If the change was greater than the threshold value. the eye was declared to be in a saccade: if less, to be fixated. When the eye was first found to be fixated after a saccade. the CRT was turned off and the display instructions were changed to create a window at the appropriate location in the text. The CRT was then turned back on. The time the display was off. with a window size of 17 characters, was $6 \mathrm{msec}$. short enough for no blink to be detected. For each 20-character increase in the window size. the CRT off time was increased by $5 \mathrm{msec}$. The largest window size. 100 character positions. required the CRT to be off for $30 \mathrm{msec}$ and produced very noticeable-blinking of the display.

Since the display was changed each time a fixation was made. the question of lag between the time the eye stopped and the detection of the eve being stopped is particularly important. Two features of the system used made this lag substantially greater than was realized at the time the study was conducted. First. the filter in the eye-movement equipment already mentioned increased the lag substantially. Second. a relatively slow sampling rate $160 \mathrm{sec}$ or 
once every 16 msec) further increased the lag. With this sampling rate. it would be quite possible for the eye to be stopped for $18 \mathrm{msec}$ prior to detecting the fixation. even with a fast-responding eye-movenent signal. If the fixation occurred at just the right time, it might be detected after only a few milliseconds. These two factors. the filter and sampling rate. resulted in a variable lag which is difficult to assess exactly, but which could have been as much as $40 \mathrm{msec}$ at times. Identification of the onset of a saccade was probably faster. Subjects did not have an experience of seeing one pattern change to an other during a fixation, however, probably due to a combined effect of visual suppression during and after saccades and of visual masking (Haber \& Hershenson, 1973).

\section{RESULTS AND DISCUSSION}

\section{The Data}

For each page of text read by each subject, summary statistics were obtained for a number of aspects of eye-movement behavior, in addition to scores on the retention test. Each fixation and saccade in the eye-behavior data was categorized as one of four types: a forward movement and fixation, a regressive movement and fixation, a forward movement and fixation in a regression (if a regression had previously been made and this forward movement failed to bring the eye back to the point from which the regression was originally made), or as a return sweep. On the movement or series of movements which advanced the eye to the next line, all movements were categorized as return sweep movements, and fixations bounded on both sides by return sweep movements were identified as return sweep fixations. The fixation occurring at the end of a return sweep, which was then followed by a forward movement, was identified as a forward fixation.

Three types of eye-movement data were analyzed. The first was time data. The reading time per 100 characters was computed for the page, and then this was broken down in two ways. First, it was broken into time spent in movement (movement time) vs. time spent in fixations (fixation time). Time spent in forward movements and in forward fixations was also obtained. Second, time was broken down by the categories of movements and fixations, yielding total time per 100 characters for forward movements and fixations, regressions, forward movements and fixations in regressions, and return sweeps.

The second type of data consisted of simple counts of the number of fixations and movements per 100 characters, both total for the entire page and broken down into forward, regression, forward in regression, and return sweep, in order to have the number of each of these types of movements and saccades that occurred.

The third type of data was measures of saccade lengths, saccade durations, and fixation durations. Saccade lengths were measured in number of character positions. First, second, and third quartiles were obtained from the distributions of all fixation durations and forward-fixation durations for each page. Second quartiles (medians) were obtained for the distributions of fixation durations for regressions, forward movements in regressions, and return sweeps. The same statistics were obtained for the distributions of saccade lengths and saccade durations, except that no statistics were included for distributions of total saccade lengths and durations. Thus, there were 34 dependent variables for which one score was obtained per page for each subject.

Effects of peripheral text pattems. For each of these variables, eight three-way analyses of variance were carried out, one for each window size. The purpose of each analysis was to determine whether at that window size the peripheral text pattern had any effect on the dependent variable. The three factors in each analysis of variance were subjects (six), letter-replacement algorithm used in producing the peripheral text pattern (called letter replacement, with three levels for $\mathrm{C}, \mathrm{NC}$, and $\mathrm{X}$ versions), and whether the peripheral text pattern had spaces and punctuation remaining or removed (called space vs. filled, with two levels for $S$ and $F$ versions). This led to a large number of analyses, a total of 272 , being carried out. Since this was bound to lead to a number of significant effects on the basis of chance alone, the following strategy was used to identify differences that were likely to be reliable. A difference was considered to be reliable if it occurred at two successive window sizes, with a significance level less than .10 at each window size, and with the data pattern at both window sizes being similar.

For most dependent variables, there was a significant main effect for subjects, and for some, subjects interacted with other variables. These effects will not be explored here, but attention will be given to main effects for letter replacement and for space vs. filled, and interactions between these two variables.

For window sizes of 31 and greater, there were no reliable effects using the above definition of reliability. Where significant effects were found at one window size, the data pattern observed at adjacent window sizes was not the same. Thus these effects were assumed to be due to chance factors. It is concluded that with a window size of 31 , there is no evidence that the readers were acquiring either word-shape or word-length pattern information from the region beyond the window. Thus, there is no evidence that this information was acquired more than 15 character positions from the point of central vision by the subjects of this experiment. One possible exception to this conclusion will be noted later.

A number of reliable main effects and interactions were found at the smaller window sizes. These are listed in Table 1. These could be broken down into four categories: variables that influenced saccade lengths, those that influenced the duration of fixations, those that influenced the number of regressions, and those that were more gross measures 
Table 1

A List of Reliable Effects Not Involving the Subject Factor

\begin{tabular}{|c|c|c|c|c|c|}
\hline Variable & $\begin{array}{l}\text { Window } \\
\text { Size }\end{array}$ & Effect* & $\begin{array}{c}F \\
\text { Value }\end{array}$ & df & $\begin{array}{c}\text { Significance } \\
\text { Level }\end{array}$ \\
\hline Forward fixation time per 100 characters & $\begin{array}{l}17 \\
21\end{array}$ & $\begin{array}{l}S \\
S\end{array}$ & $\begin{array}{r}31.60 \\
4.14\end{array}$ & $\begin{array}{l}1,5 \\
1,5\end{array}$ & $\begin{array}{l}.003 \\
.10\end{array}$ \\
\hline Forward movement and forward fixation time per 100 characters & $\begin{array}{l}17 \\
21\end{array}$ & $\begin{array}{l}S \\
S\end{array}$ & $\begin{array}{r}30.33 \\
4.47\end{array}$ & $\begin{array}{l}1,5 \\
1,5\end{array}$ & $\begin{array}{l}.004 \\
.09\end{array}$ \\
\hline Number of fixations per 100 characters & $\begin{array}{l}13 \\
17 \\
13 \\
17\end{array}$ & $\begin{array}{l}\text { S } \\
\text { S } \\
\text { SL } \\
\text { SL }\end{array}$ & $\begin{array}{r}5.91 \\
11.49 \\
3.29 \\
3.41\end{array}$ & $\begin{array}{l}1,5 \\
1,5 \\
2,10 \\
2,10\end{array}$ & $\begin{array}{l}.06 \\
.02 \\
.08 \\
.07\end{array}$ \\
\hline Number of forward fixations per 100 characters & $\begin{array}{l}13 \\
17 \\
21\end{array}$ & $\begin{array}{l}S \\
S \\
S\end{array}$ & $\begin{array}{r}19.06 \\
41.53 \\
4.60\end{array}$ & $\begin{array}{l}1,5 \\
1,5 \\
1,5\end{array}$ & $\begin{array}{l}.008 \\
.002 \\
.08\end{array}$ \\
\hline Number of regressive fixations per 100 characters & $\begin{array}{l}13 \\
17 \\
25\end{array}$ & $\begin{array}{l}\text { L } \\
\text { L } \\
\text { L }\end{array}$ & $\begin{array}{l}5.67 \\
3.87 \\
5.60\end{array}$ & $\begin{array}{l}2,10 \\
2,10 \\
2,10\end{array}$ & $\begin{array}{l}.02 \\
.06 \\
.02\end{array}$ \\
\hline Saccade length-second quartile & $\begin{array}{l}13 \\
17\end{array}$ & $\begin{array}{l}S \\
S\end{array}$ & $\begin{array}{r}3.94 \\
13.36\end{array}$ & $\begin{array}{l}1,5 \\
1,5\end{array}$ & $\begin{array}{l}.10 \\
.02\end{array}$ \\
\hline Saccade length-third quartile & $\begin{array}{l}13 \\
17 \\
21 \\
25\end{array}$ & $\begin{array}{l}S \\
S \\
S \\
S\end{array}$ & $\begin{array}{r}21.87 \\
24.79 \\
18.65 \\
6.27\end{array}$ & $\begin{array}{l}1,5 \\
1,5 \\
1,5 \\
1,5\end{array}$ & $\begin{array}{l}.006 \\
.005 \\
.008 \\
.06\end{array}$ \\
\hline Saccade length of regressions-second quartile & $\begin{array}{l}13 \\
17\end{array}$ & $\begin{array}{l}\text { SL } \\
\text { SL }\end{array}$ & $\begin{array}{l}8.48 \\
8.01\end{array}$ & $\begin{array}{l}2,10 \\
2,10\end{array}$ & $\begin{array}{l}.007 \\
.009\end{array}$ \\
\hline Duration of forward movements-second quartile & $\begin{array}{l}13 \\
17\end{array}$ & $\begin{array}{l}S \\
S\end{array}$ & $\begin{array}{l}5.91 \\
9.35\end{array}$ & $\begin{array}{l}1,5 \\
1,5\end{array}$ & $\begin{array}{l}.06 \\
.03\end{array}$ \\
\hline Duration of forward fixations-first quartile & $\begin{array}{l}21 \\
25\end{array}$ & $\begin{array}{l}\text { SL } \\
\text { SL }\end{array}$ & $\begin{array}{l}7.81 \\
8.00\end{array}$ & $\begin{array}{l}2,10 \\
2,10\end{array}$ & $\begin{array}{l}.009 \\
.009\end{array}$ \\
\hline Duration of forward fixations-second quartile & $\begin{array}{l}17 \\
21\end{array}$ & $\begin{array}{l}\mathrm{L} \\
\mathrm{L}\end{array}$ & $\begin{array}{l}3.51 \\
4.47\end{array}$ & $\begin{array}{l}1,5 \\
1,5\end{array}$ & $\begin{array}{l}.07 \\
.04\end{array}$ \\
\hline Duration of regressive fixations - second quartile & $\begin{array}{l}21 \\
25\end{array}$ & $\begin{array}{l}\mathrm{L} \\
\mathrm{L}\end{array}$ & $\begin{array}{l}5.58 \\
4.20\end{array}$ & $\begin{array}{l}1,5 \\
1,5\end{array}$ & $\begin{array}{l}.02 \\
.05\end{array}$ \\
\hline
\end{tabular}

* $S$ indicates significant effect for spaces vs. filled, $L$ indicates significant effect for letter replacement, $S L$ indicates a significant interaction.

of eye behavior and hence were affected by the three categories already mentioned.

Saccade lengths were affected only by the presence or absence of spaces in the peripheral text pattern. Figure 2 presents the average first, second, and third quartiles for the distributions of saccade lengths for the $S$ and $F$ peripheral text patterns, together with an indication of the significant effects. As can be seen, when word-length patterns were eliminated from the peripheral text pattern by filling the spaces, the saccades tended to be shorter. This effect is most noticeable at the third quartile, indicating that it tended primarily to reduce the number of long saccades, thus constricting the distribution of saccade lengths at the high end, rather than simply shifting the entire distribution down. The difference between $S$ and $F$ versions is present at least up to a window size of 25. and may be present even further, though the difference there is not significant. It appears, then, that word-length pattern information is acquired at least as far as 12 character positions $(3 \mathrm{deg}$ ) from the center of vision, and perhaps even farther, and may be used in guiding the eye during reading.

A significant main effect for spaces vs. filled was also found for saccade duration data at the three smallest window sizes. With word-length pattern eliminated from the peripheral text pattern, saccades were of shorter duration, which of course simply reflects the fact that saccades were of shorter distance under these conditions, as already noted.

The average length of regressive saccades also

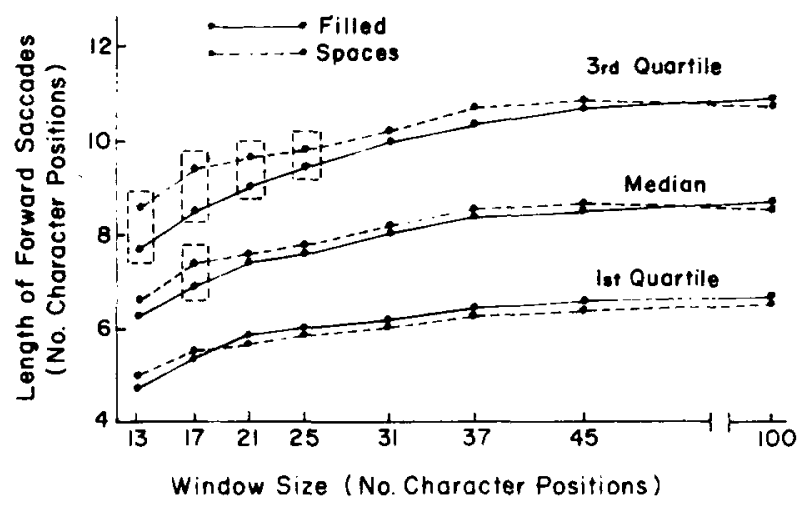

Figure 2. The length of forward saccades as a function of window size and of the presence or absence of word-length information in the peripheral text pattern; first, second, and third quartiles. 
tended to be less when word-length information was eliminated from the peripheral text pattern, though the difference was signiticant only at window size 17 . The Spaces vs. Filled by Letter Replacement interaction was significant at the .01 level for regression saccade length data at the two smallest window sizes, but the data pattern changed greatly between the two window sizes, so these interactions will not be considered reliable or explored further. There was a tendency for the XS condition to produce particularly short regressive saccades at the 17,21 , and 25 window sizes, with saccade lengths for that condition being more like those of the filled conditions than the other spaces conditions.

While lengths of saccades were influenced primarily by the presence or absence of word-length pattern in the peripheral visual areas, the duration of fixations was influenced largely by letter replacement. Significant main effects for letter replacement were found for the second and third quartiles of the distributions of forward-fixation durations and for the third quartile for total fixation durations at window sizes 17 and 21. The forward fixation-duration data are presented in Figure 3. Total fixation-duration data are almost identical. From this figure, it can be seen that there tends to be a small difference in the duration of fixations between the $C$ and $\mathrm{NC}$ letter-replacement conditions at the two smallest window sizes, but that this difference disappears at window size 21 . At the smaller sizes, having improper word-shape patterns in the peripheral text pattern intlates the fixation durations slightly. With window size 21 , however, it seems to make no difference whether the peripheral text pattern presents accurate or inaccurate word-shape information, suggesting

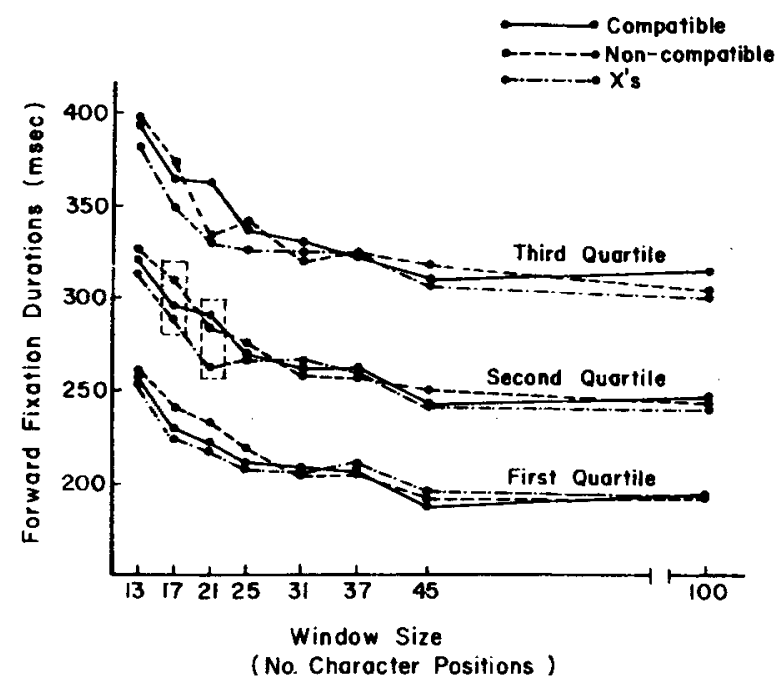

Figure 3. The duration of forward fixations as a function of window size and of the presence or absence of word-shape information in the peripheral text pattern: first, second, and third quartiles. that general word-shape information is not acquired by these readers as much as 10 character positions from the point of central vision.

At the three smallest window sizes, the $X$ letter-replacement condition leads to the lowest fixation durations. The $\mathrm{X}$ condition has the characteristic that the boundaries of the windows are well marked; the contrast between the normal text in the window region and the homogeneous $x$ pattern in the peripheral area is very noticeable. Thus, it would seldom happen that a reader would make the error of attempting to integrate letters from outside the window in to the text pattern within the window itself. On the other hand, with the $\mathrm{C}$ and $\mathrm{NC}$ letter-replacement conditions, the boundaries of the window are not at all obvious, and the reader undoubtedly quite frequently picks up letters from outside the window area and attempts to integrate these with the normal text in the window, thus producing some disruption. This disruption likely leads to the longer durations for the $C$ and $N C$ conditions as compared to the $\mathrm{X}$ conditions. If this is so, then the fact that there is a difference in fixation durations between the $\mathrm{X}$ and the $\mathrm{C}$ and NC conditions at window size 21 suggests that the reader is picking up specific letter information under the $C$ and $N C$ conditions as much as 10 character positions from his point of central vision. These differences disappear at window size 25 , suggesting that this type of visual information is not being acquired by the readers at 12 character positions from the point of central vision.

The first quartile forward fixation duration data showed a Spaces vs. Filled by Letter Replacement interaction at window sizes 21 and 25 . However, the data pattern was not consistent from one window size to the next, so these interactions will not be considered reliable.

This consideration of the fixation duration data leads to two conclusions: first, the subjects acquired specific letter information no more than 10 or 11 character positions $\left(2 \frac{1}{2} \mathrm{deg}\right)$ from the point of central vision, and second, general word-shape information was not acquired any further into the periphery than this either. Thus, word-shape patterns, other than word-length characteristics, appear to be acquired no further into the periphery than is specific visual information needed to identify letters.

The number of regressions made by subjects per 100 characters was reliably affected by the letter-replacement pattern. Significant main effects are shown in Figure 4 . Here it is seen that the $\mathrm{C}$ condition produced the most regressions, whereas the $X$ condition produced the least. The reason for this difference is not known, though it may have something to do with the naturalness of the appearance of the peripheral text pattern. The least natural-appearing pattern was the one which led to the fewest regressions.

The differences in saccade length, fixation 
duration, and number of regressions produced by the variables resulted in differences in other more gross measures of eye behavior in reading. A significant main effect for spaces vs. filled was found at window sizes 13 and 17 for total reading time per 100 characters, total time spent in forward movements and fixations per 100 characters, total number of fixations per 100 characters, total number of forward fixations per 100 characters, total time spent in fixations per 100 characters, and total time spent in forward fixations per 100 characters. The latter variable also showed a significant effect at window size 21 . These data will not be presented in detail, since they simply resulted from the previously noted effects of the variables on specific eye-behavior masures and by themselves ad nothing to the understanding of the reading processes involed.

General effects of window size. Higure 5 shows the effect of window size on the time required to read the text. The dependent variable is time required to read 100 characters. Reducing the window sizc eaused this time to rise from 4.33 to $6.92 \mathrm{sec}$, a $60 \%$ increase. This increase resulted primarily from an increase in the amount of time the eye was fixated; total time in movement rose $10 \%$, while total time spent in fixations rose $76 \%$. As seen in earlier figures, this increase was a result of the subjects' making both more fixations (a $33 \%$ increase from 12.82 fixations per 100 characters to 16.98 ) and fixations of longer durations (a $31 \%$ increase from $245 \mathrm{msec}$ median forward fixation duration to $320 \mathrm{msec}$ ). The larger number of fixations was entirely the result of readers making shorter forward saccades, with median saccade length dropping from 8.76 to 6.43 character positions. There was no increase in the number of regressive movements as the window size was reduced. The median number of regressive movements per 100 characters ranged from 1.1 to .9 for the different window sizes. Thus, the increase in reading time with smaller window sizes was not due to a change in the number of regressions, but was the result of changes in the normal forward saccade and fixation pattern.

As seen in Figure 5, reading time continued to drop as window sizes became larger, and reached asymptote only at the largest sizes. Median saccade lengths and fixation durations showed the same pattern. This change may be due to either of two types of influence: (1) either subjects were obtaining some useful visual information from the normal text from regions as wide as 45 character positions, which was not available in the peripheral text patterns, or (2) reducing the window size itself changed the reader's behavior or produced artifacts which were reflected in his eye-movement behavior. The first of these possibilities does not seem likely in view of the earlier-reported results from this experiment. The evidence seemed to indicate that the readers were not obtaining word-shape or specific letter information

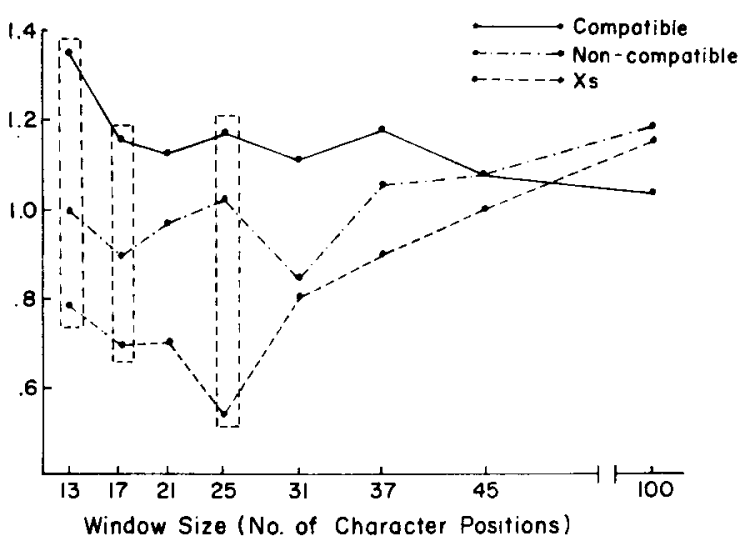

Figure 4. The number of regressive movements per 100 characters as a function of window size and of the presence or absence of word-shape information in the peripheral text pattern.

from a region extending more than about 10 or 11 character positions from the point of central vision, and that they were not acquiring word-length pattern information more than about 15 character positions into the periphery. If this is so, it is difficult to imagine what other visual characteristics of the text might be acquired further into the periphery which were not present in the peripheral text patterns. Therefore, it will be assumed that the continued drop in the reading time and other curves with increased window size has some other basis.

Among the many possible reasons why reducing the window size might produce the effects noted, two seem particularly likely. One possibility is that subjects have the ability to control the size and location of the general area from which they acquire visual information on each fixation during reading. Thus, as the window became smaller, they may have tended to constrict their field of visual attention to a narrower region. This may also have caused them to

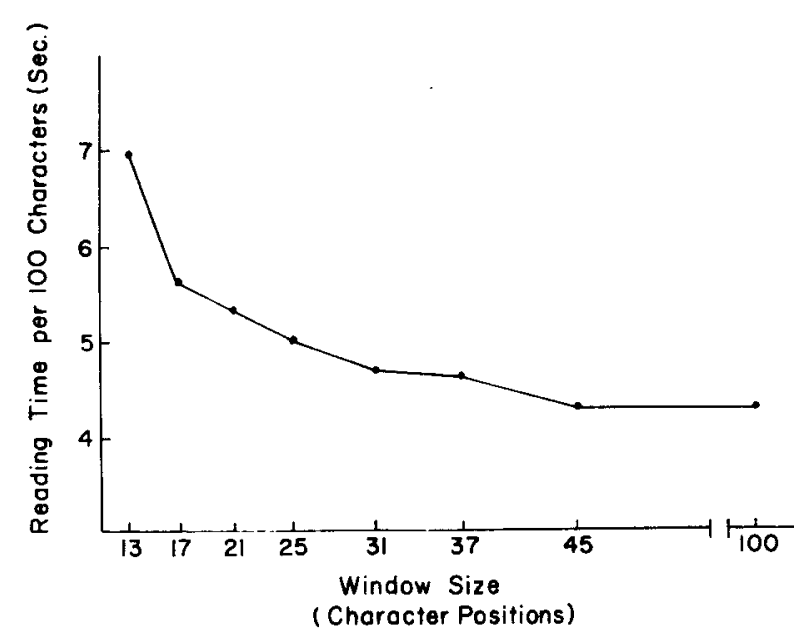

Figure 5. Effect of window size on time to read 100 characters of text. 
make shorter saccades and perhaps even longer fixations as the window became smaller, but at the same time would not have led to differences in reading behavior as a function of type of peripheral text pattern. If this explanation were in fact correct, it would invalidate the previous conclusions about the size of the region from which the subjects tended to pick up visual information: the results found would be typical only of subjects reading under conditions which forced them to narrow their range of attention during each fixation.

The second possibility why smaller window sizes produced the effects noted is related to the lag discussed earlier in identifying the onset of a fixation and producing the display changes required for this rescarch. It was noted there that at times the display change might not have occurred for as much as $40 \mathrm{msec}$ following the actual eye-fixation onset. Even though this is within the time when visual masking was likely occurring as one stimulus pattern replaced another, it is possible that the display changes taking place in the periphery were sufficiently distracting to produce changes in the eye-movement patterns, causing longer fixations and producing more short saccades. With small window sizes, these changes would be taking place closest to central vision, where they might be expected to have the most disrupting effect. As the window became larger, the changes were being made further and further into the periphery, where their effect, while still present, was reduced. Thus, reading patterns may have been affected somewhat by these display changes taking place even some distance from the point of central vision.

At present, the authors tend to accept this latter explanation. There are two reasons for this. First. Reder (personal communication) has conducted similar research under conditions with substantially less lag in producing the display change, and he reports that the curves asymptote much earlier in his studies. This suggests that the delayed asymptote in our research was not due to a narrowing of the field of attention, since if it were, the same phenomenon would be expected to be present in Reder's data. Rather, it is probably due to the relative slowness with which our display changes were taking place. Second, Rayner (1975) has reported a study which did not involve the type of display changes used in the present study, and which would not tend to induce the reader to narrow his field of attention. He reported results concerning the size of the perceptual span in reading which are quite compatible with the estimates from the present study. Thus, it is concluded that the window-size effects were probably due to artifacts produced by the display change itself rather than to changes in the width of the field of attention.

Retention test performance. The retention tests were constructed to have two questions taken from the information on each page of text. This made it possible to carry out a four-way analysis of variance on retention test scores to determine whether the variables influenced the subjects' retention of information from the passages. The only significant effect was the Window Size by Subjects interaction $(F$ $=1.553, p<.03,35$ and $288 \mathrm{df}$ ). Window size did not have an effect on test performance $(F=1.371$, $p<.25,7$ and $35 \mathrm{df}$ ). The significant interaction was plotted to determine whether there was a tendency for some subjects, but not for others, to perform more poorly with smaller window sizes. No such tendency could be found. The interaction seemed to arise primarily from lack of complete counterbalancing in the experiment due to the small number of subjects in relation to the large number of passages. Curves for individual subjects were very irregular across window sizes, with no observable trends.

\section{GENERAL DISCUSSION}

This experiment has provided data which begin to answer the question about the size of the perceptual span during a fixation in reading. Although it may be possible in tasks other than reading for subjects to identify letters, word shapes, and word-length patterns some distance into the peripheral areas, in fluent reading this information appears to be obtained and used from a relatively narrow region. Thus, a theory of thuent reading need not suppose that word-shape and specific letter information is obtained from a region occupied by more than about three or four words during a fixation, and perhaps not that large if the span is not symmetrical around the point of central vision, a question not tested in the present study. Thus, it does not appear to be true that entire sentences are seen during a fixation; in fact, for most fixations, not even a complete phrase will lie within this area.

It has often been suggested that poor comprehension in reading can be the result of a narrow perceptual span. Smith (1971), for instance, suggests that having a narrow span, thus perceiving snaller groups of words at a time, results in the cognitive processing system having to deal with more "chunks" of information. This is said to produce a heavier load on the processing system, which reduces the reader's ability to see relationships in the text, thus reducing comprehension of the text. It is of interest, then, that reducing the perceptual span of the readers in this study by reducing the size of the window, although it slowed their reading considerably, did not reduce their comprehension test scores. Thus, no evidence was found for the notion that a reduced perceptual span produces reduced comprehension.

The fact that word-length patterns are acquired somewhat further into the periphery than the more 
specific letter and word-shape information, and that the presence or absence of this aspect of the visual pattern in the periphery is related to saccade length, is harmonious with the position that the eye is guided during reading on the basis of characteristics of the peripheral visual pattern (Hochberg, 1970). The nature of this guidance is presently unknown, but it is of interest that we have found informally that people can mark phrase boundaries in text fairly reliably when all letters have been replaced by xs. Thus word-length patterns are related to syntactic structure to some degree.

For the subjects studied here, saccades of median length carry the eye to a location just short of the furthest point where letter- and word-shape information tend to be acquired. This means that a large proportion of the saccades carry the eye beyond that point. Further studies need to explore whether the span for features of the text on which interpretation can be based is symmetrical or asymmetrical, which will indicate the degree to which this span overlaps from fixation to fixation. Finally, further study is also needed to investigate whether useful visual information is acquired from other lines than the one being directly fixated in reading.

Although many questions about the nature of the perceptual spans during reading remain unanswered, the present study suggests that a technique involving manipulating the display on the basis of eye-position information may have the power to provide answers to these questions.

\section{REFERENCE NOTE}

1. McConkie, G. W.. \& Rayner. K. Identifying the span of the effective stimulus in reading. Final Report OEG2-71-0531,
U.S. Office of Education. 1974. This report is available from ERIC Document Reproduction Service.

\section{REFERENCES}

Bouma. H. Visual recognition of isolated lower-case letters. Vision Resiarch, 1971. 11, 459-474.

Bouma. H. Visual interference in the parafoveal recognition of initial and final letters of words. Vision Research. 1973. 13. $767-782$

Bouma, H.. \& DeVoogd, A. H. On the control of eye saccades in reading. Vision Reseurch, 1974, 14, 273-284.

HABer, R. N.. \& Hershenson. M. The psychology of visual perception. New York: Holt. Rinehart \& Winston. $197 \dot{3}$.

Hochaerg. J. Components of literacy: Speculations and exploratory research. In $\mathrm{H}$. Levin and J. P. Williams (Eds.). Basic studie's on reading. New York: Basic Books. 1970.

HODGE. D. C. Legibility of a uniform-stroke width alphabet: 1. Relative legibility of upper and lower-case letters. Joumal of Engineering Psychology. 1962. 1. 34-46.

HuEY. E. B. The psychology and pedagogy of reading. New York: Macmillan. 1908.

Mackworth. H. H. Visual noise causes tunnel vision. Psychonomic Science. 1965, 3. 67-68.

Newman. E. B. Speed of reading when the span of letters is restricted. American Journal of Psychology, 1966, 79. 272-278.

Poulton. E. C. Peripheral vision, refractoriness and eye movements in fast oral reading. British Joumal of Psychology. 1962. 53. 409-419.

RAYNER. K. The perceptual span and peripheral cues in reading. Cognitive Psychology. 1975, 7. 65-81.

REDER, S. M. On-line monitoring of eye position signals in contingent and noncontingent paradigms. Behavior Research Methods \& Instrumentation, 1973. 5. 218-228.

SMITH, F. Understanding reading. New York: Holt, Rinehart \& Winston. 1971.

Woodworth, R. S, Experimental psychology. New York: Holt. 1938.

(Received for publication January 24. 1975; revision received March 3. 1975.) 